\title{
DEVELOPMENTAL DYSLEXIA: A CONDENSED REVIEW OF LITERATURE
}

\author{
Anna Belavina Kuerten ${ }^{*}$ \\ Mailce Borges Mota ${ }^{1 *}$ \\ ${ }^{1}$ Universidade Federal de Santa Catarina, Florianópolis, SC, Brasil \\ Katrien Segaert ${ }^{2 * * *}$
}

${ }^{2}$ Centre for Human Brain Health, University of Birmingham, Birmingham, Reino Unido

\begin{abstract}
In this article we provide a condensed review of literature on developmental dyslexia. Starting with the historical background to this language-based reading disorder, we discuss four key components for a valid and operational definition of developmental dyslexia. We then present the major theoretical explanations of developmental dyslexia in order to gain a better understanding of the causes of this reading disorder. These causal explanations are addressed in the context of Morton and Frith's (1995) model. Four major theories of developmental dyslexia are discussed: the phonological deficit theory, the double-deficit theory, the magnocellular theory, and the cerebellar theory. The last section of this review addresses the model of reading development proposed by Frith (1986). Understanding the developmental progression of children's abilities in reading is crucial in order to detect in which phase of this progression a breakdown attributed to dyslexia occurs.

Keywords: Developmental Dyslexia; Dyslexic Children; Acquisition of Reading
\end{abstract}

\footnotetext{
"PhD in English (Federal University of Santa Catarina, Brazil). Email: abelavina@gmail.com. ORCID: https:// orcid.org/0000-0003-4957-4534

" $\mathrm{PhD}$ in English (Federal University of Santa Catarina, Brazil). Full Professor in the Department of Foreign Languages and Literatures (Federal University of Santa Catarina, Brazil). Research fellow of the Brazilian National Council for Scientific and Technological Development (CNPq) and founding member of the Brazilian Network of Science for Education.Email: mailce.mota@ufsc.br. ORCID: https://orcid.org/0000-0002-86742480

${ }^{* * *} \mathrm{PhD}$ in Social Sciences (Radboud University Nijmegen, the Netherlands). Lecturer in the School of Psychology and affiliated with the Centre for Human Brain Health at the University of Birmingham. Email: k.segaert@ bham.ac.uk. ORCID: https://orcid.org/0000-0002-3002-5837
} 


\section{Developmental dyslexia: a bit of history}

The word dyslexia is of Greek origin: the prefix $d y s$ means difficult and the root, lexia, means words. Therefore, the literal translation of dyslexia is difficulty with words (Payne \& Turner, 1999). The German professor Rudolf Berlin, an ophthalmologist working in Stuttgart, coined this term in 1887 to refer to a group of six adult patients who had lost their ability to read (Shaywitz, 2003). ${ }^{1}$ These adult patients attracted the attention of Berlin, who monitored them for twenty years. Based on a postmortem analysis, Berlin detected brain lesions in the left hemisphere and associated these lesions to difficulties in reading.

Earlier clinical evidence for similar behavior in reading was described by the term word-blindness (Wortblindheit in German),[which was] coined by another German physician, Adolf Kussmaul, in 1877. Interested in neurologically impaired adults with reading difficulties, he observed patients who demonstrated poor ability to recognize written words after having suffered cerebral vascular injury. Of interest was the fact that the patients' intelligence, fluency in speaking, and eyesight were not affected by the injury they had suffered. The physician was puzzled by the fact that these abilities remained intact and, seeking to understand the problem, he continued further investigations of lesions around the left angular gyrus, a region of the brain in the parietal lobe. Based on his findings, Kussmaul concluded that a lesion in the left angular gyrus was responsible for reading difficulties. Therefore, Kussmaul was the first scientist to associate reading disability with a lesion in this brain region.

Other clinicians such as the German physician Johann Schmidt, the British neurologist William Broadbent, and the French neurologist Joseph Dejerine also reported cases of dyslexia (Elliott \& Grigorenko, 2014; Ott, 1997; Shaywitz, 2003). ${ }^{2}$ However, it is important to bear in mind that these clinicians described atypical reading patterns in adults who had achieved normal levels of reading skills; i.e., prior to brain lesions these adults were literate. Today, this condition is termed acquired dyslexia. Acquired dyslexia, which is also termed alexia, is a reading disorder which emerges in premorbidly literate individuals who lose previously developed reading skills after brain injury (Leong \& Joshi, 2013). Similar atypical reading patterns are also observed in people who have never achieved the expected reading level. The term developmental dyslexia applies to this condition. In light of this, the nature of reading disability in acquired dyslexia and developmental dyslexia is different (Jackson \& Coltheart, 2001).

Noteworthy, there are reasons to be wary of claims that acquired dyslexia is always related to adults and brain damage as its cause, while developmental dyslexia is only encountered in school-aged children (Jackson \& Coltheart, 2001). Cumulative evidence from case studies on dyslexia has revealed that age and brain damage are not necessarily associated with the type of dyslexia. For example, there are cases of children who, despite being typical readers and demonstrating progress in the development of reading skills, suddenly lose their reading ability and competence. This is a case of acquired dyslexia. On the other 
hand, an elderly woman at the age of 80 who has always had great difficulties with reading is an example of developmental dyslexia, not acquired dyslexia, because she has never been a competent reader.

Additionally, brain damage is not always indicative of acquired dyslexia because there are cases of acquired dyslexia in which brain damage is not necessarily the source of reading difficulties. Jackson and Coltheart (2001) give an example of a man who used to be a skilled reader, but one day he woke up and perceived his difficulties in reading. Neither alterations in brain function, nor brain damage were detected in this patient. Nevertheless, his case received the diagnosis of acquired dyslexia. As regards developmental dyslexia, alterations in brain function associated with defective brain maturation are central to the explanation of this reading disorder (Habib, 2000; Shaywitz et al., 2002).

The first report of developmental dyslexia, entitled A case of Congenital Word Blindness, was published by the British physician Dr. William Pringle Morgan in 1896 (Shaywitz, 2003; Snowling, 2000). In his report, Morgan described a 14-year-old boy named Percy F. as a case of developmental dyslexia (Cook \& Ryan, 2016). Despite being bright and intelligent, quick at games, the boy had severe difficulties in learning to read. Percy struggled with reading simple sentences, making mistakes in every single word, except for articles, prepositions and conjunctions. Moreover, he made many spelling errors, including in his own name, which he used to spell as Precy. Morgan also tested his ability to read numbers and do mathematical operations like multiplication and was puzzled by the fact that the boy performed these tasks easily. In light of accumulated evidence, Morgan concluded that Percy's inability to learn to read was due to a congenital alteration in the left angular gyrus, since similar difficulties were observed in adults with injury in this region. ${ }^{3}$

With the passage of years, more cases of developmental dyslexia were reported in Europe and the United States (Elliott \& Grigorenko, 2014; Shaywitz, 2003). During the 1920s one of the most prominent was the American neurologist Dr. Samuel Torrey Orton. His influential work Reading, Writing and Speech Difficulties in Children was published in 1937. Orton proposed a theory of cerebral dominance suggesting that, in dyslexics, neither hemisphere was dominant and that would explain basic symptoms of developmental dyslexia, such as reversals of letters, syllables, and words. Even though his hypothesis was refuted, many of his observations had a profound impact on understanding dyslexia and sparkled a great deal of debate in the literature (Høien \& Lundberg, 2000). One year after Orton's death in 1948, the Orton Dyslexia Society was founded with the mission to continue his work on the prevention, treatment, and study of this disorder. The Orton Dyslexia Society is the former name of the International Dyslexia Association (IDA), a non-profit education and advocacy organization dedicated to this reading disorder in the USA.

As can be seen from this brief historical account, research on dyslexia began more than a century ago and since then important contributions have been made to dyslexia research (Jackson \& Coltheart, 2001). Today, there is a general 
consensus that developmental dyslexia is a disorder of neurobiological origin characterized by difficulties in reading and writing skills (Cook \& Ryan, 2016). With advanced neuroimaging techniques (fMRI, EEG, MEG), it is possible to detect neuronal abnormalities associated with this disorder. However, despite a plethora of reports with detailed descriptions of the behavioral symptoms observed in developmental dyslexia, the definition of dyslexia has been subject of debate over the last 50 years. Researchers agree that developmental dyslexia may have several underlying causes and is generally accompanied by other developmental disorders, such as attention deficit hyperactivity disorder (ADHD) (Joshi \& Aaron, 2016). Various definitions of developmental dyslexia have been proposed. The next section aims at presenting important characteristics of developmental dyslexia, which should be accounted for its definition.

\section{Definitions of dyslexia}

Despite years of research, there is still considerable debate on the appropriate definition for developmental dyslexia (Castles \& Coltheart, 1993; Fisher \& DeFries, 2002; Fletcher, 2009; Lyon et al., 2003). Much disagreement concerns the underlying causes of developmental dyslexia (hereafter, dyslexia), which in turn also implicates appropriate forms of assessment. Rice and Brooks (2004) reviewed over 1200 book chapters and papers and analyzed many definitions of dyslexia. The researchers distinguish two types of definitions: descriptive and explanatory (Rice \& Brooks, 2004). Descriptive definitions of dyslexia are those that purely describe developmental difficulties, such as poor word decoding (reading) and encoding (spelling). This type of definition aims at facilitating the early diagnosis of dyslexia, which in turn leads to early intervention. However, descriptive definitions lack explanatory elements with respect to possible underlying causes of dyslexia. Explanatory definitions rely on explanatory theories. What type of definition is the most applicable remains a contentious issue among researchers and clinicians.

Tunmer and Greaney (2010) sought to contribute to this debate by providing answers to three interrelated questions: What is dyslexia? What causes it? What can be done about it? (p. 229). According to the researchers, the conceptualization of how dyslexia is defined, what causes difficulties in learning to read, and which intervention is the most effective is strongly influenced by a broader conceptualization of what reading is and how it is acquired. On the basis of answers to the above question, Tunmer and Greaney (2010) strongly advocate that the plausible definition of dyslexia should encompass the following four components: (1) persistent literacy learning difficulties, (2) exclusionary factors, (3) exposure to evidence-based instruction and intervention, and (4) inclusionary factors.

A definition that encompasses these four components is the one developed by a working group of the International Dyslexia Association (Lyon et al., 2003). The definition of Lyon and colleagues (2003) is commonly accepted and cited 
in the literature of dyslexia (Elliott \& Grigorenko, 2014; Fletcher, 2009). The following definition is an updated version of their working definition of 1994:

Dyslexia is a specific learning disability that is neurobiological in origin. It is characterized by difficulties with accurate and/or fluent word recognitionand by poor spelling and decoding abilities. These difficulties typically result from a deficit in the phonological component of language that is often unexpected in relation to other cognitive abilities and the provision of effective classroom instruction. Secondary consequences may include difficulties in reading comprehension and reduced reading experience that can impede growth of vocabulary and background knowledge (Lyon et al., 2003, p.2).

This definition provides essential characteristics of dyslexia. In the opening sentence of the definition, Lyon and colleagues (2003) refer to the specificity of dyslexia towards learning skills as well as to its neurobiological origin. It is noteworthy that this definition also goes beyond the established view of dyslexia as single word decoding difficulties. Decoding abilities of pseudowords, ${ }^{4}$ for instance, and poor spelling are also considered as a manifestation of reading comprehension difficulties and reduced reading experience. These consequences, in turn, may lead to limited growth in vocabulary and background knowledge. The definition of Lyon and colleagues (2003) also includes the core causal explanation of dyslexia, the phonological processing deficit, which is not related to intelligence and classroom instruction.

It is important to state that traditionally, clinicians have identified dyslexic individuals with the help of standardized tests that measure intelligence and cognitive abilities in order to attest that literacy learning difficulties of dyslexics are not directly caused by low intelligence. ${ }^{5}$ As a consequence, many definitions of dyslexia hold with the idea of the discrepancy-based criterion, i.e., the discrepancy between mental age, measured by an intelligence quotient (IQ), and reading age, measured by standardized tests of reading accuracy and comprehension, in comparison to chronological age (Bishop \& Snowling, 2004; Fletcher, 2009; Lyon et al., 2003; Ramus, 2003). An example of a discrepancy-based definition is that proposed by an influential diagnostic system, the ICD-10 Classification of Mental and Behavioural Disorders (Health Organization-WHO, 1993).

\section{Theories of developmental dyslexia}

The definition and explanation of dyslexia have become a matter of debate, in which the nature and features of this disorder are central (Elliott \& Grigorenko, 2014). In order to achieve a better understanding of this disorder, the first step is to distinguish between the different levels of existing explanation for dyslexia. Morton and Frith (1995) have proposed a causal model, which clearly distinguishes the three major levels of explanation: biological, cognitive, and behavioral. By providing full causal explanation for this disorder, this causal model has become 
widely acknowledged and commonly referenced (Frederickson, 2009; Nicolson \& Fawcett, 2008; Pavey, 2007; Snowling, 2000). Here we describe this causal model and discuss current explanatory theories of dyslexia in the context of the model. The choice to address theories of dyslexia by means of Morton and Frith's (1995) model is attributed to the fact that it brings together different levels of explanation, thus contributing to a thorough understanding of dyslexia.

The lack of an agreed definition as well as the debate over the underlying causes of dyslexia motivated two developmental psychologists, John Morton and Uta Frith, to think about a neutral framework, which would compare different theories of development disorders and find the common ground between them (Morton \& Frith, 1995). The framework proposed by Morton and Frith (1995) incorporates three levels of explanation: the biological level, the cognitive level, and the behavioral level. According to Morton and Frith (1995), all three levels are equally important and complement each other. Additionally, the researchers included environmental factors in the framework, as these may have an impact on one or all of these levels.

It is well assumed that clinicians diagnose dyslexia based on specific behavioral manifestations. Morton and Frith (1995) suggest that all behavioral manifestations of dyslexia should be associated with the behavioral level of the framework. Given that dyslexia is a disorder of neurobiological origin, Morton and Frith (1995) pay special attention to the differences, in the neurobiological substrates, between dyslexic and typically developing individuals. The biological level, which is the deepest level of explanation of dyslexia, includes contributions from genetic and brain imaging research. There is evidence from molecular genetics that a number of inherited genes (for example, DYX1C1, KIAA0319, DCDC2 and ROBO1) may contribute to the development of dyslexia (Fisher \& DeFries, 2002; Fisher \&Francks, 2006). Additionally, dyslexia is a congenital neurobiological disorder caused by abnormal brain structure, in particular abnormal magnocellular pathways and abnormal cerebellum (Shastry, 2007). These brain abnormalities are associated with explanation at the biological level of the framework.

According to Morton and Frith (1995), valuable contributions to the understanding of dyslexia come from the cognitive level, where causes of dyslexia are associated with deficient information-processing mechanisms. Current theoretical explanations of dyslexia at the cognitive level include deficits in shortterm or working memory, phonological awareness, incomplete automatization, and slow processing (Reid, Soler, \& Wearmouth, 2003). For instance, there is a general consensus about the phonological deficit theory, which suggests that the core deficit in dyslexia is related to phonological processing (Ramus et al., 2003).

Overall, Morton and Frith (1995) highlight the importance of each level as well as of environmental factors when analyzing different explanatory perspectives on dyslexia. The researchers claim that investigating causes of dyslexia at the proposed levels as well as causal links between these levels will be helpful in understanding and explaining this disorder. In addition, this framework integrates 
the potentially disparate theoretical accounts of dyslexia, which may seem to be in conflict with each other at first sight. An example of this is an integration of two commonly referenced theories that explain dyslexia as resulting from a phonological deficit and from a magnocellular deficit, respectively. As previously stated, the phonological deficit theory is associated with the cognitive level of explanation, where a deficit in phonological processing is the source of reading difficulties among dyslexics. The magnocellular deficit theory, in turn, assumes that there is alteration in the magnocellular system of dyslexics, which causes reading difficulties. This theory is attributed to the biological level of explanation. From the perspective of Morton and Frith's (1995) model, both theories are compatible with each other, and not mutually exclusive. The researchers claim that theoretical explanations should not be confined to a particular level of the framework: they may originate at one level and extend to others.

Taking into account a range of causal explanations at the biological and cognitive levels, Morton and Frith's (1995) emphasize the importance of considering not only behavioral manifestations for a diagnosis of dyslexia, such as poor reading accuracy and speed, but also evidence of alterations in brain function and cognitive deficits. According to Morton and Frith (1995), contemporary theories of dyslexia may be modelled in the three-level framework. Next we address some of these theories, which explain neurocognitive causes of dyslexia.

\section{The phonological deficit theory}

Over the 40 last years, research in dyslexia has accumulated robust empirical evidence in support of both the phonological deficit in dyslexia and effective intervention programs based on phonological training (Lyon et al., 2003; Fawcett \& Nicolson, 1995; Joanisse et al., 2000; Ramus, 2003; Snowling, 1995). The description of the phonological processing deficit comprises three main components: poor phonological awareness, poor verbal short-term memory and slow lexical retrieval (Ramus, 2004).

Phonological processing difficulties in dyslexics are well-documented (Ramus, 2003; Snowling, 2000; Vellutino et al., 2004). These difficulties are especially detectable in task requiring phonological awareness, i.e., the ability to manipulate speech sounds (phonemes) and their combinations (syllables) consciously (Ramus, 2004). Having poor phonological awareness, dyslexic individuals have difficulties in performing tasks such as syllable counting, phoneme deletion or substitution. A deficit in phonological processing manifests in tasks that require memory for phonological sequences (Ramus, 2004). Dyslexics demonstrate severe difficulties in tasks aimed at remembering sequences of sounds or letters or repeating non-words. The phonological processing deficit also affects lexical retrieval, which is an undeniable skill for reading (Ramus, 2004). Dyslexics are seriously challenged by tasks that require the ability to name aloud letters or objects rapidly. According to Ramus (2004), phonological awareness, verbal short-term memory, and lexical retrieval are responsible for the representation, 
storage, and retrieval of linguistic material, i.e., information processing at the cognitive level. Failures in one or all of these abilities may explain a variety of behavioral manifestations in dyslexia.

In terms of the causal model proposed by Morton and Frith (1995), the behavioral signs of a phonological deficit are associated with alterations in the lefthemisphere language system (Démonet, Taylor, \& Chaix, 2004). In particular, there are abnormal responses in the left inferior frontal region with increased activation, the left parietal-temporal regions and the left inferior temporal-occipital regions with reduced activation during both phonological and reading tasks (Démonet et al., 2004; Hoeft et al., 2006; Shaywitz \& Shaywitz, 2005). Importantly, difficulties in phonological processing are neither related to auditory impairments, where an individual cannot reproduce a sound due to inadequate hearing, nor to visual impairments caused by physical difficulties with the eyes.

The model also predicts that various environmental factors, such as orthography, teaching methods, and literacy values, have a strong impact on the acquisition of grapheme-phoneme knowledge. For instance, the type of orthography may influence the developmental progress of children learning to read (Vellutino et al., 2004). Languages with opaque orthographies, i.e., languages with no consistent relationship between graphemes and phonemes, such as English, present a significantly greater challenge to many beginning learners than languages with transparent orthographies, i.e., languages with consistent relationship between graphemes and phonemes, such as German or Italian. Moreover, teaching methods play an important role in building phonological skills, and societal values strongly influence the acquisition of literacy acquisition.

The phonological deficit theory has become the most commonly referenced theoretical explanation of dyslexia. Although this theory provides a reasonable and coherent explanation of dyslexia, controversy still exists because not all dyslexics demonstrate difficulties in phonological processing. The main criticism of the phonological deficit theory is that it typifies the idea of a phonological deficit as exclusive in nature. In the next subsection, the role of two distinct cognitive deficits responsible for information processing, i.e., a phonological deficit and a rapid-naming deficit, is addressed in terms of the double-deficit theory.

\section{The double-deficit theory}

A number of scholars defend the notion that dyslexics' difficulties are not exclusively or mainly associated with a deficit in phonological processing (Lovett, Steinbach, \& Frijters, 2000; Wimmer, Mayringer, \& Landerl, 2000; Wolf \& Bowers, 2000). Therefore, the double- deficit theory, which is an extension of the dominant phonological deficit theory, has been proposed (Wolf \& Bowers, 2000). The double-deficit theory recognizes the role of phonological processing skills for reading development. However, according to this theory, dyslexics have a deficit in rapid serial/automatized naming (RAN), which is an equally important skill for reading development. The double-deficit theory proposes 
that dyslexic individuals have a single deficit in one of these skills or the double deficit in both skills.

Based on extensive investigations, Wolf and Bowers (2000) claim the existence of three subtypes of dyslexic readers: the first subtype exhibiting a single deficit in phonological skills, but intact naming speed, the second subtype exhibiting a single naming-speed deficit, but intact phonological skills, and the third subtype exhibiting a double deficit, when both phonological and rapid-naming skills are impaired. A phonological deficit has a strong relationship with decoding accuracy, whereas a naming-speed deficit is strongly associated with reading fluency.

An important implication of this theory is that individuals with a single naming-speed deficit require adequate intervention, not solely based on the training of phonological skills. In line with this, training phonological skills may not be so effective for languages with transparent orthographies. For instance, in languages like Italian and German, in which skills in phonological processing play a less important role, naming speed becomes a powerful predictor of reading performance (Nijakowska, 2010). Noteworthy is the evidence that individuals with a double deficit, i.e., with difficulties in both reading accuracy and speed, are the most severely impaired subtype, thus suggesting a more intensive intervention based on training both phonological and rapid-naming skills.

The double-deficit theory has been intensely investigated by providing a substantial body of evidence for its main assumptions (Lovett et al., 2000; Wolf, Bowers, \& Biddle, 2000). For instance, Lovett and colleagues (2000) conducted a study with 166 children with severe reading disabilities with age ranging from 7 to 13 years old. The researchers aimed at categorizing children's difficulties according to the presence or absence of a phonological and naming-speed deficit (Lovett et al., 2000). The data of $84 \%$ of the sample ( 140 children) were submitted to further analysis, revealing that $54 \%$ of the sample demonstrated a double deficit, $24 \%$ had a single naming-speed deficit and $22 \%$ had a phonological deficit. It should be noted that children with the double deficit were more severely impaired in comparison to children with single deficits. Based on evidence in support to a double deficit in dyslexic individuals, Wolf and colleagues (2000) argue that a phonological deficit is not the only core deficit in dyslexia. There is a second core naming speed deficit, which influences reading performance in terms of fluency. According to the researchers, intervention programs for dyslexics should include practices on both skills (Wolf et al., 2000).

In hindsight, the two theories of dyslexia presented above have a causal explanation at the cognitive level. According to Morton and Frith (1995), the cognitive level constitutes a crucial link between the biological and behavioral levels, with underlying causes of cognitive deficits arising from structural abnormalities of the brain. Owing to the assumption of a causal model of Morton and Frith (1995), behavioral manifestations of language processing difficulties in dyslexia are caused by brain abnormalities. Therefore, the dyslexic brain has attracted researchers' attention as the likely source of language processing difficulties (Galaburda, 2005; Habib, 2000; Shaywitz et al., 2002; Shaywitz \& Shaywitz, 2005). 
Before discussing the theoretical explanations of dyslexia in relation to alterations in the brain, it is important to give credit to the earliest investigations of the dyslexic brain. Norman Geschwind, an American neurologist, had the idea to undertake neuroanatomical analysis of dyslexic brains and compare them to those of non-dyslexics (Galaburda, 2005). As stated by Galaburda (2005) in his review article, Geschwind confirmed a left-right hemisphere asymmetry in volume of the planum temporale in dyslexics and explained this finding as insufficient amount of brain tissues in the left hemisphere, which is heavily involved in language processing. Geschwind hypothesized that an insufficiency of brain tissues in the left hemisphere could be triggered by an improper development of language regions in fetus, particularly during the migration of young neurons to their final destination in the brain.

Geschwind's ideas were further investigated by Galaburda and colleagues (Galaburda, Sherman, Rosen, Aboitiz, \& Geschwind, 1985), who were among the first interested in the brain organization of dyslexic individuals. Galaburda's group observed neural abnormalities (ectopias), i.e., dismigration and disorganization of the neurons, in many areas of dyslexic cerebral cortex, especially in language areas in the left hemisphere. A plausible account of ectopias in combination with a phonological deficit is that anomalous neural development is more pronounced in the language areas of the left hemisphere, particularly the perisylvian region.

Interesting findings were revealed comparing four male and three female dyslexic brains (Galaburda et al., 1985; Humphreys, Kaufmann, \& Galaburda, 1990). The number of participants was limited as these were two postmortem investigations. The researchers concluded that the location of neural abnormalities was different in males and females. In dyslexic males, the brain showed symmetry of the planumtemporale and predominantly left-sided microscopic abnormalities in the cerebral cortex. Regarding the female dyslexic brain, the researchers also concluded that the brain had a symmetrical planumtemporale, but there were fewer abnormalities, which varied in location, when compared to the brain of male dyslexics (Humphreys et al., 1990). It is important to state that the planumtemporale in typically developing individuals has a leftward asymmetry with greater size (Bloom, Garcia-Barrera, Miller, Miller, \& Hynd, 2013).

During the last decade brain imaging techniques, such Magnetoencephalography (MEG), and functional Magnetic Resonance Imaging (fMRI), havebeen extensively used to investigate dyslexia (Baillieux et al., 2009; Beneventi, TøNnessen, Ersland, \& Hugdahl, 2010; Buchweitz et al., 2019; Hoeft et al., 2011; Norton, Beach, \& Gabrieli, 2014; Richards \& Berninger, 2008; Rimrodt et al., 2009; S. Shaywitz et al., 1998; Shaywitz et al., 2002). With the help of this technique, researchers have had the opportunity to observe brain activity during online processing tasks. Brain imaging data have received targeted attention in order to enhance our understanding of dyslexia, and two theoretical explanations have emerged: the magnocellular deficit theory and the cerebellar deficit theory. These two theories are discussed next. 


\section{The magnocellular deficit theory}

Reading involves fast and accurate visual identification of letters and words. According to Stein (2001), the visual system is crucial to reading, and dyslexia is the result of abnormalities in the neural pathways of this system. The visual system is divided into two distinct pathways: the magnocellular and the parvocellular (Greatrex \& Drasdo, 1995) pathways. Each pathway has different functions and properties. The magnocellular pathway is responsible for the fast input transmission from the retina to the occipital and parietal brain regions, and the parvocellular pathway processes the details of this input.

In the magnocellular deficit theory, poor reading performance of dyslexics is due to abnormally reduced sensitivity in the magnocellular system (Livingstone, Rosen, Drislane, \&Galaburda, 1991; Lovegrove, Bowling, Badcock, \& Blackwood, 1980; Skottun, 2000; Stein et al., 2000). In particular, the visual sensory abnormalities are the result of magnocells shrinkage (magnocells are about 27\% smaller in dyslexics) and disorganization in lateral geniculate nucleus, whereas the parvocells are intact (Greatrex \& Drasdo, 1995;Livingstone et al., 1991). A reduced ability to detect visual stimuli rapidly can result in visual stress. Thus, dyslexics manifest a variety of symptoms of visual stress, such as headaches, eye strain, poor concentration, difficulty to remember what has been read, omission of words and lines when reading (Kelly \& Phillips, 2016).

In terms of the causal model proposed by Morten and Frith (1995), there are causal connections between abnormalities in the magnocellular system and behavioral signs of dyslexia. Fluency and accuracy in reading are dependent on fast and accurate processing of both visual and auditory information. As Stein (2001) proposes, dyslexics have lower sensitivity to both visual and auditory stimuli in comparison to typically developing individuals. At the cognitive level, difficulties of dyslexics are attributed to a general temporal processing dysfunction. As a consequence, this dysfunction leads to a visual magnocellular deficit and an auditory deficit. The temporal auditory deficit is thought to cause a deficit in phonological processing. At the behavioral level, the visual magnocellular deficit explains dyslexics' difficulties with tasks that require the perception of motion. Difficulties associated with the temporal auditory deficit are poor tone discrimination, poor speech development, and poor reading.

In addition to the visual and auditory deficits, the magnocellular deficit theory also explains the cerebellar deficit in dyslexics (Stein, 2001). Taking into account that the cerebellum receives information from the magnocellular system, the cerebellum is also affected by a more general magnocellular dysfunction. Thus, the cerebellar deficit theory has been proposed, which is reviewed next.

\section{The cerebellar deficit theory}

The cerebellum has been traditionally viewed as the area involved in learning and the automatization of motor skills (Nicolson \& Fawcett, 2008; Stein 
\& Glickstein, 1992). However, during the last two decades the assumption that the cerebellum might be involved in cognitive skills, particularly in language processing, has gained support (Fabbro, Moretti, \& Bava, 2000; Justus \& Ivry, 2001; Marien, Engelborghs, Fabbro, \& De Deyn, 2001). Recent brain imaging studies have provided evidence to this assumption by detecting activation in the cerebellum during reading tasks (e.g., Carreiras, Mechelli, Estévez, \& Price, 2007; Joubert et al., 2004; Mechelli, Gorno-Tempini, \& Price, 2003).Based on the converging evidence for cerebellar dysfunction in dyslexics, Nicolson and Fawcett (2008) proposed the cerebellar deficit theory. According to Nicolson and Fawcett (2008), dyslexic individuals fail to develop automaticity in reading skills due to a dysfunction in the cerebellum. In particular, this dysfunction was reported in brain imaging studies as a reduced activation in the right cerebellum confirming that the magnocellular deficit also affects the cerebellum (Nicolson et al., 1999; Rae et al., 1998).

Frith (1999) proposes a causal connection between cerebellar alterations and behavioral signs of dyslexia. An impaired cerebellum implies a temporal processing deficit at the cognitive level. Slower-than-normal temporal processing is associated with deficits in phonological and motor skills. At the behavioral level, the motor control deficit explains poor naming speed, poor time estimation, poor motor development, and poor balance. Difficulties associated with the phonological deficit are poor naming speed and poor reading.

Altogether, the cerebellar deficit theory treats dyslexia as a general learning disability (Nicolson, Fawcett, \& Dean, 1995; Nicolson, Fawcett, \& Dean, 2001). Difficulties in reading and writing are caused by a deficit in the cerebellum, which is responsible for skill automatization. Therefore, the supporters of the cerebellar theory claim that difficulties in phonological processing and motor skills experienced by dyslexics should be attributed to a dysfunction in the cerebellum (Fawcett \& Nicolson, 1994; Nicolson, Fawcett, \& Dean, 1995; Nicolson, 1994). The cerebellar deficit theory as well as the magnocellular deficit theory explain the phonological deficit as caused by a more general temporal processing deficit, thus suggesting that intervention at the sensory level can also be helpful (Tallal et al., 1996).

We will now move on to a review of the model proposed by Frith (1986), which describes the developmental progression of children's abilities in reading and accounts for the breakdown in this progression that is associated with dyslexia

\section{Typical reading development}

There has been considerable interest in the reading literature about children 's progress in reading development (Elbro, 1996; Kirby, Desrochers, Roth, \& Lai, 2008; Nation \& Snowling, 1998), and a developmental model of reading can serve many purposes. First, a developmental model can inform about crucial abilities for reading, such as decoding, as well as explain the developmental progression of these abilities. Moreover, a developmental model can establish the relation between reading and cognitive abilities involved in this process. 
An example of such model is the one proposed by Uta Frith (1986), which is currently one of the most prominent and influential models of literacy development (Gathercole \& Baddeley, 2014). Frith's model of reading development takes into account her research and practice about children's learning to read (Nunes \& Bryant, 2013). Although it was proposed more than three decades ago, this model is widely accepted and commonly referenced by many scholars and still is considered applicable today (Adelman, 2012; Beaton, 2004; Hulme \& Snowling, 2013). The model describes how typically developing reading abilities change and progress while children learn to read an alphabetic orthography such as English. According to the model, in order to reach success in reading, children should go through three phases: the logographic phase, the alphabetic phase, and the orthographic phase (Frith, 1986).

During the logographic phase, children`s earliest attempts to read take place. However, these attempts do not involve a phonological strategy, since letter sequence is neglected, and are based on a purely visual strategy. Children recognize familiar words relying on highly distinctive visual cues such as size, shape, and length. In other words, children memorize words as visual entities, called logographs. Using this visual strategy, children are able to read or perceive words that are significant to them and are stored in their limited vocabulary. For instance, children recognize their own names, names of shops, and common signs. However, the strategy is not always reliable and, because it is not generative, it will not help them read unfamiliar words later. At this early phase of literacy development, children are not aware of the alphabetic principle, i.e., understanding that individual graphemes and their combinations correspond to certain sounds. The chronological age of children associated with this phase may vary from 3 to 5 years old (Bielby, 1999).

Having quite good experience with the visual forms of words, children's visual discrimination abilities become more refined. It is in the second phase-the alphabetic phase--that children develop the notion of alphabetic principle. Unlike the first phase, the alphabetic strategy does not usually develop spontaneously. Children need to be exposed to some kind of formal instruction from more competent readers, such as parents, relatives, and teachers, who can explain to them the grapheme-to-phoneme conversion rules. This input motivates children to analyze the relationship between graphemes and sounds in spoken and written words. The chronological age of children attributed to this phase may vary from 5 to 7 years old (Bielby, 1999).

The alphabetic phase plays a crucial role in the development of the subsequent orthographic strategy. In the orthographic phase, children develop the orthographic strategy, which enables them to recognize words automatically and access their meaning immediately from the lexical memory. Word recognition and word retrieval occur without much effort because children are able to break down words into orthographic segments automatically without graphemeto-phoneme conversion, i.e., without sounding out each grapheme as in the alphabetic phase. The orthographic segments correspond to morphemes that 
are stored in memory. The analysis of words into orthographic segments takes place much faster than the phonological analysis. Frequent words are decoded and read much faster than infrequent ones. The chronological age of children attributed to this phase may vary from 7 to 9 years old (Bielby, 1999).

According to Frith (1986), typical literacy acquisition is characterized by the progression in each phase and the development of each strategy in the above mentioned sequence. The progress and change from one phase to the next one are not random. They are the consequence of biological (maturation) and cultural (teaching) influence. The expected outcome of this sequential development is a competent reader who demonstrates fluency and accuracy in reading. Importantly, this fixed sequential development is not restricted to the use of one strategy independently and once at a time. Sometimes children may employ two different strategies at the same time, in particular when they still do not have full control of a new strategy and use aprevious strategy on their way to adapt to a new condition.

Another relevant issue that Frith (1986) raises in her model of reading development is that, over the course of learning, children do not always demonstrate gradual improvement in reading. At any moment of their reading development, children may have a decline in performance because the transition from one phase to another implies the acquisition of a new strategy and its integration with the already acquired strategy. The transition through phases is very sensitive and delicate and may be associated with either breakthrough or breakdown. According to Whitebread (2002), the advantage of this model is that the defined phases are quite useful and practical for instructors because they can monitor the progress made by children at a particular phase and identify whether there is some nonconformity or decline in progression, whether the decline is temporal or long-lasting, and whether early intervention is mandatory.

Although the model proposed by Frith (1986) has particular authority in the literature on reading development, it has also received criticism (Beech, 2005; Graham \& Kelly, 2012). The main criticism comes from Ehri (1995) and has to do with inadequacies in Friths' definition of each phase. For instance, Ehri (1995, p. 118) states that the term logographic is misleading "because beginners in the first phase do not read words like mature readers of logographic orthographies such as Chinese". According to Ehri (1995), the concept of alphabetic processing is crucial to the definition of developmental phases in reading. Therefore, she proposes a new model of reading development consisting of four phases that are distinguished by the involvement of the alphabetic system. The phases are labelled pre-alphabetic, partial alphabetic, full alphabetic, and consolidated alphabetic. The pre-alphabetic phase is equivalent to Frith`s logographic phase. Frith 's (1986) alphabetic phase is divided by Ehri (1995) into two: partial and full. According to Ehri (1995), the difference between these two phases lies in the ability to map graphemes to phonemes: whereas in the partial alphabetic phase this ability is initial, in the full alphabetic phase it is fully developed. Despite the criticism of Ehri (1995), the model proposed by Frith (1986) is currently one of 
the most influential developmental models of reading (Gathercole \& Baddeley, 2014) and has also been adopted to explain developmental disorders of reading like dyslexia (Høien \& Sundberg, 2000; Mortimore \& Dupree, 2008; Uodej, 2016).

The idea that reading strategies are acquired at different time courses and in a fixed and continuous sequence enables the identification of a developmental failure within one of these strategies. According to Frith (1986), the failure may be observed at different phases, and the type of developmental disorder will depend on where exactly the failure occurs. It is reasonable to suggest that in the presence of a failure, the child tries to develop some compensatory strategies. If the child faces difficulties at one particular phase, the child may over-develop a previously acquired strategy in order to compensate for these difficulties, or $\mathrm{s} / \mathrm{he}$ may simulate the use of a necessary strategy for a certain performance. Under the last presupposition, a simulated behavior like guessing words from context is easily detectable because it requires more time and, hence, reduces fluency, accuracy, prosody, and also comprehension (Mather \&Wendling, 2011). A failure in developing a new strategy should receive a parsimonious explanation because not all children may advance from one phase to the following one at the same or similar pace. Noteworthy, this temporal developmental delay should not be considered a developmental disorder.

When comparing developmental delay and developmental disorder, Frith (1986) argues that the crucial difference is about the time course of children's difficulties. In developmental delay, the strategy is acquired slowly and difficulties are overcome by the end of each phase, whereas in developmental disorder, despite the use of compensatory strategies, difficulties still persist. An example of the second condition is the case of successful dyslexics who manage to develop good reading abilities after having been exposed to effective intervention and training, but who still need to make great effort while reading, in comparison to typical readers (Frith, 1999). For this reason, dyslexia must be defined in terms of a developmental disorder and not in terms of a developmental delay, because in developmental delay the difficulty is no longer detectable in the following phase (Frith, 1999).

Additionally, Frith (1986) also claims that the gravity of a reading disorder depends on where (which developmental phase) a failure occurs, i.e., the later the failure, the less severe the disorder. Moreover, Frith (1986) states that it is not possible to fail at one phase and succeed in the next phase. For instance, the child cannot learn the orthographic strategy if $s /$ he has failed the previous strategy, i.e., the alphabetic strategy, which serves as the basis for the next one. According to Frith (1986), a failure in acquiring the alphabetic strategy results in dyslexia. The researcher also explains that dyslexic individuals are able to master the logographic strategy, but there is a failure to develop the alphabetic strategy, in which the grapheme-to-phoneme correspondence rules are at stake. In other words, dyslexics cannot make progress beyond the logographic phase because they cannot grasp the alphabetic grapheme-to-phoneme associations. In a similar vein, they also face great difficulty to move on to the orthographic 
phase, in which fluency in reading is mastered, because they have not succeeded in the previous phase.

\section{Conclusion}

Developmental dyslexia is the most common developmental language disorder of neurological origin in school-aged children with normal intelligence and sensory abilities (Baillieux et al., 2009; Fisher \& Defries, 2002; Fletcher, 2009; Petterson \& Pennington, 2015; Vellutino et al., 2004). The estimates of the affected school age population around the world vary from 5 to 17 and it is estimated that $80 \%$ of all individuals diagnosed with some type of learning disability are dyslexic (D’Mello \& Gabrieli, 2018). Consequently, dyslexia may be considered an epidemiology in our society, where literacy skills are crucial. This explains why dyslexia has attracted much attention and why it is important to understand the nature of this language disorder.

Dyslexia manifests itself in reading and writing difficulties in different languages, be they alphabetic, like English, or non-alphabetic, like Chinese. Although dyslexia has been studied for more than 100 years, it is still a challenge for professionals to identify this specific reading disability, explain its underlying causes and, as a result, provide effective intervention (e.g., Démonet et al., 2004; Fisher \& DeFries, 2002; Fletcher, 2009; Nicolson \& Fawcett, 2008; Tunmer \& Greaney, 2010; Vellutinoet al., 2004). With this condensed review, we hope to have highlighted the basics about dyslexia by presenting the historical background to the research on this disorder, summarizing important theories of dyslexia, and addressing an influential model of reading development.

\section{Acknowledgements}

The authors are grateful to CAPES, for a grant to ABK (Cod. 001) and MBM (CAPES/NUFFIC Program Project 051/13), to CNPq for the research fellowship to MBM, and to the Newton Fund/British Academy to a mobility grant to KS.

\section{Notes}

1. The term dyslexia was presented first in 1887 by Professor Dr. Rudolf Berlin in his monograph Einebesondere Art der Wortblindheit (Dyslexie).

2. It is important to give special credit to Thomas Willis, an English physician and neuroanatomist, who described clinically the first case of dyslexia in his work $D e$ Anima Brutorum (Of the Soul of Brutes) in 1672 (Critchley, 1996; apud Ott, 1997).

3. Another clinician, the British doctor James Kerr, shares the credit for the first report of developmental dyslexia. Kerr publicly presented his ideas in 1896, reporting his observation of children who had failed to learn to read and write. Similarly to Percy F., those children had no other cognitive deficits. Kerr, thus, diagnosed them with congenital word-blindness (Ott, 1997).

4. Here, a distinction needs to be made between pseudowords and non-words, which are also frequently employed in the lexical decision task or the word naming task used to assess phonological processing abilities (Thomson, Crewther, \& Crewther, 2006). Pseudowords are pronounceable strings of letters, which resemble real words, 
but have no meaning (e.g., wird), whereas non-words are non-pronounceable strings of letters formed in a random order (e.g., dsrte).

5. Tests like the Wechsler Adult Intelligence Scale (WAIS) and Wechsler Intelligence Scale for Children (WISC) are used to measure reasoning skills and problem-solving abilities in adults and children, respectively.

\section{References:}

Adelman, J. S. (2012). Visual Word Recognition Volume 2: Meaning and Context, Individuals and Development. London and New York: Psychology Press.

Baillieux, H., Vandervliet, E. J. M., Manto, M., Parizel, P. M., Deyn, P. P. D., \& Mariën, P. (2009). Developmental dyslexia and widespread activation across the cerebellar hemispheres. Brain and Language, 108(2), 122-132.

Beaton, A. (2004). Dyslexia, Reading and the Brain: A Sourcebook of Psychological and Biological Research. London and New York: Psychology Press.

Beech, J. R. (2005). Ehri's model of phases of learning to read: A brief critique. Journal of Research in Reading, 28(1), 50-58.

Beneventi, H., TøNnessen, F. E., Ersland, L., \& Hugdahl, K. (2010). Executive working memory processes in dyslexia: Behavioral and fMRI evidence: Working memory deficit in dyslexia. Scandinavian Journal of Psychology, 51(3), 192-202.

Bielby, N. (1999). Teaching Reading: Key Stage 2. Cheltenham: Nelson Thornes.

Bishop, D. V. M., \& Snowling, M. J. (2004). Developmental Dyslexia and Specific Language Impairment: Same or Different? Psychological Bulletin, 130(6), 858-886.

Bloom, J. S., Garcia-Barrera, M. A., Miller, C. J., Miller, S. R., \& Hynd, G. W. (2013). Planum Temporale Morphology in Children with Developmental Dyslexia. Neuropsychologia, 51(9), 1684-1692.

Buchweitz, A., Costa, A. C., Toazza, R., de Moraes, A. B., Cara, V. M., Esper, N. B., ... Franco, A. R. (2019). Decoupling of the Occipitotemporal Cortex and the Brain's Default-Mode Network in Dyslexia and a Role for the Cingulate Cortex in Good Readers: A Brain Imaging Study of Brazilian Children. Developmental Neuropsychology, 44(1), 146-157. https://doi.org/10.1080/87565641.2017.1292516

Carreiras, M., Mechelli, A., Estévez, A., \& Price, C. J. (2007). Brain Activation for Lexical Decision and Reading Aloud: Two Sides of the Same Coin? Journal of Cognitive Neuroscience, 19(3), 433-444.

Castles, A., \& Coltheart, M. (1993). Varieties of developmental dyslexia. Cognition, 47(2), 149-180.

Cook, V., \& Ryan, D. (2016). The Routledge Handbook of the English Writing System. New York: Routledge.

Démonet, J.-F., Taylor, M. J., \& Chaix, Y. (2004). Developmental dyslexia. The Lancet, 363(9419), 1451-1460.

D’Mello, A. \& Gabrieli, J.D.E. (2018). Cognitive neuroscience of dyslexia. Language, Speech, and Hearing Services in Schools, 49, 798-809.

Ehri, L. C. (1995). Phases of development in learning to read words by sight. Journal of Research in Reading, 18(2), 116-125.

Elbro, C. (1996). Early linguistic abilities and reading development: A review and a hypothesis. Reading and Writing, 8(6), 453-485.

Elliott, J. G., \& Grigorenko, E. L. (2014). The Dyslexia Debate. Cambridge University Press. 
Fabbro, F., Moretti, R., \& Bava, A. (2000). Language impairments in patients with cerebellar lesions. Journal of Neurolinguistics, 13(2-3), 173-188.

Fawcett, A. J., \& Nicolson, R. I. (1994). Naming Speed in Children with Dyslexia. Journal of Learning Disabilities, 27(10), 641-646.

Fawcett, A. J., \& Nicolson, R. I. (1995). Persistent Deficits in Motor Skill of Children with Dyslexia. Journal of Motor Behavior, 27(3), 235-240.

Fisher, S. E., \& DeFries, J. C. (2002). Developmental dyslexia: genetic dissection of a complex cognitive trait. Nature Reviews Neuroscience, 3(10), 767-780.

Fisher, S. E., \& Francks, C. (2006). Genes, cognition and dyslexia: learning to read the genome. Trends in Cognitive Sciences, 10(6), 250-257.

Fletcher, J. M. (2009). Dyslexia: The evolution of a scientific concept. Journal of the International Neuropsychological Society, 15(04), 501.

Frederickson, N. (2009). Special Educational Needs, Inclusion and Diversity. Maidenhead: McGraw-Hill Education (UK).

Frith, U. (1986). A developmental framework for developmental dyslexia. Annals of Dyslexia, 36(1), 67-81.

Frith, U. (1999). Paradoxes in the definition of dyslexia. Dyslexia, 5(4), 192-214.

Galaburda, A. M. (2005). Dyslexia-A molecular disorder of neuronal migration. Annals of Dyslexia, 55(2), 151-165.

Galaburda, A. M., Sherman, G. F., Rosen, G. D., Aboitiz, F., \& Geschwind, N. (1985). Developmental dyslexia: four consecutive patients with cortical anomalies. Annals of Neurology, 18(2), 222-233.

Gathercole, S. E., \& Baddeley, A. D. (2014). Working Memory and Language. Psychology Press.

Graham, J., \& Kelly, A. (2012). Reading Under Control: Teaching Reading in the Primary School. Routledge.

Greatrex, J. C., \& Drasdo, N. (1995). The magnocellular deficit hypothesis in dyslexia: a review of reported evidence. Ophthalmic and Physiological Optics, 15(5), 501506.

Habib, M. (2000). The neurological basis of developmental dyslexia. Brain, 123(12), 2373-2399.

Hoeft, F., Hernandez, A., McMillon, G., Taylor-Hill, H., Martindale, J. L., Meyler, A., Gabrieli, J. D. E. (2006). Neural Basis of Dyslexia: A Comparison between Dyslexic and Nondyslexic Children Equated for Reading Ability. Journal of Neuroscience, 26(42), 10700-10708.

Hoeft, F., McCandliss, B. D., Black, J. M., Gantman, A., Zakerani, N., Hulme, C., ... Gabrieli, J. D. E. (2011). Neural systems predicting long-term outcome in dyslexia. Proceedings of the National Academy of Sciences of the United States of America, 108(1), 361-366. https://doi.org/10.1073/pnas.1008950108.

Høien, T., \& Lundberg, I. (2000). Dyslexia: From Theory to Intervention. Kluwer Academic Publishers.

Høien, T., \& Sundberg, P. (2000). Dyslexia: From Theory to Intervention. Springer Science \& Business Media.

Hulme, C., \& Snowling, M. J. (2013). Developmental Disorders of Language Learning and Cognition. John Wiley \& Sons.

Humphreys, P., Kaufmann, W. E., \& Galaburda, A. M. (1990). Developmental dyslexia in women: neuropathological findings in three patients. Annals of Neurology, 28(6), 727-738. 
Jackson, N. E., \& Coltheart, M. (2001). Routes To Reading Success and Failure: Toward an Integrated Cognitive Psychology of Atypical Reading. London and New York: Psychology Press.

Joanisse, M.F., Manis, F.R., Keating, P. and Seidenberg, M.S. (2000). Language deficits in dyslexic children: Speech perception, phonology and morphology. Journal of Experimental Child Psychology 71, 30-60.

Joshi, R. M., \& Aaron, P. G. (2016). Handbook of Orthography and Literacy. Routledge.

Joubert, S., Beauregard, M., Walter, N., Bourgouin, P., Beaudoin, G., Leroux, J. M., Lecours, A. R. (2004). Neural correlates of lexical and sublexical processes in reading. Brain and Language, 89(1), 9-20.

Justus, T. C., \& Ivry, R. B. (2001). The cognitive neuropsychology of the cerebellum. International Review of Psychiatry, 13(4), 276-282.

Kelly, K., \& Phillips, S. (2016). Teaching Literacy to Learners with Dyslexia: A Multisensory Approach. SAGE.

Kirby, J. R., Desrochers, A., Roth, L., \& Lai, S. S. V. (2008). Longitudinal predictors of word reading development. Canadian Psychology/Psychologie Canadienne, 49(2), 103-110.

Leong, C. K., \& Joshi, R. M. (2013). Developmental and Acquired Dyslexia: Neuropsychological and Neurolinguistic Perspectives. Springer Science \& Business Media.

Livingstone, M. S., Rosen, G. D., Drislane, F. W., \& Galaburda, A. M. (1991). Physiological and anatomical evidence for a magnocellular defect in developmental dyslexia. Proceedings of the National Academy of Sciences of the United States of America, 88(18), 7943-7947.

Lovegrove, W. J., Bowling, A., Badcock, D., \& Blackwood, M. (1980). Specific reading disability: differences in contrast sensitivity as a function of spatial frequency. Science, 210(4468), 439-440.

Lovett, M. W., Steinbach, K. A., \& Frijters, J. C. (2000). Remediating the core deficits of developmental reading disability: a double-deficit perspective. Journal of Learning Disabilities, 33(4), 334-358.

Lyon, G. R., Shaywitz, S. E., \& Shaywitz, B. A. (2003). A definition of dyslexia. Annals of Dyslexia, 53(1), 1-14.

Marien, P., Engelborghs, S., Fabbro, F., \& De Deyn, P. P. (2001). The Lateralized Linguistic Cerebellum: A Review and a New Hypothesis. Brain and Language, 79(3), 580-600.

Mather, N., \& Wendling, B. J. (2011). Essentials of Dyslexia Assessment and Intervention. John Wiley \& Sons.

Mechelli, A., Gorno-Tempini, M. L., \& Price, C. J. (2003). Neuroimaging studies of word and pseudoword reading: consistencies, inconsistencies, and limitations. Journal of Cognitive Neuroscience, 15(2), 260-271.

Mortimore, T., \& Dupree, J. (2008). Dyslexia-friendly Practice in the Secondary Classroom. Learning Matters.

Morton, J., \& Frith, U. (1995). Causal modeling -- A structural approach to developmental psychopathology. In D. Cicchetti \& D. Cohen (Eds.), Developmental Psychopathology (pp. 357-390). New York: Wiley.

Nation, K., \& Snowling, M. J. (1998). Semantic Processing and the Development of Word-Recognition Skills: Evidence from Children with Reading Comprehension Difficulties. Journal of Memory and Language, 39(1), 85-101. 
Nicolson, R. I. (1994). Reaction times and dyslexia. The Quarterly Journal of Experimental Psychology Section A, 47(1), 29-48.

Nicolson, R. I., Fawcett, A. J., Berry, E. L., Jenkins, I. H., Dean, P., \& Brooks, D. J. (1999). Association of abnormal cerebellar activation with motor learning difficulties in dyslexic adults. The Lancet, 353(9165), 1662-1667.

Nicolson, R. I., Fawcett, A. J., \& Dean, P. (1995). Time estimation deficits in developmental dyslexia: evidence of cerebellar involvement. Proceedings. Biological Sciences, 259(1354), 43-47.

Nicolson, R. I., Fawcett, A. J., \& Dean, P. (2001). Developmental dyslexia: the cerebellar deficit hypothesis. Trends in Neurosciences, 24(9), 508-511.

Nicolson, Roderick I., \& Fawcett, A. J. (2008). Dyslexia, Learning and the Brain. Cambrigde, MA, MIT Press.

Nijakowska, J. (2010). Dyslexia in the Foreign Language Classroom. Multilingual Matters.

Norton, E. S., Beach, S. D., \& Gabrieli, J. DE. (2014). Neurobiology of dyslexia. Current Opinion in Neurobiology, 30C, 73-78. https://doi.org/10.1016/j.conb.2014.09.007.

Nunes, T., \& Bryant, P. (2013). Handbook of Children's Literacy. Springer Science \& Business Media.

Ott, P. (1997). How to Detect and Manage Dyslexia: A Reference and Resource Manual. Heinemann.

Pavey, B. (2007). The Dyslexia-Friendly Primary School: A Practical Guide for Teachers. SAGE.

Payne, T., \& Turner, E. (1999). Dyslexia: A Parents' and Teachers' Guide. Multilingual Matters.

Petterson, R. \& Pennington, B. (2015). Developmental dyslexia. Annual Review of Clinical Psychology, 11, 283-307.

Rae, C., Lee, M. A., Dixon, R. M., Blamire, A. M., Thompson, C. H., Styles, P., ... Stein, J. (1998). Metabolic abnormalities in developmental dyslexia detected by 1H magnetic resonance spectroscopy. Lancet (London, England), 351(9119), 1849-1852.

Ramus, F. (2003). Developmental dyslexia: specific phonological deficit or general sensorimotor dysfunction? Current Opinion in Neurobiology, 13(2), 212-218.

Ramus, F. (2004). Neurobiology of dyslexia: a reinterpretation of the data. Trends in Neurosciences, 27(12), 720-726.

Ramus, F., Rosen, S., Dakin, S. C., Day, B. L., Castellote, J. M., White, S., \& Frith, U. (2003). Theories of developmental dyslexia: insights from a multiple case study of dyslexic adults. Brain, 126(4), 841-865.

Reid, G., Soler, J., \& Wearmouth, J. (2003). Meeting Difficulties in Literacy Development: Research, Policy and Practice. Routledge.

Rice, M., \& Brooks, G. (2004). Developmental dyslexia in adults: a research review. London: National Research and Development Centre for adult literacy and numeracy.

Richards, T. L., \& Berninger, V. W. (2008). Abnormal fMRI connectivity in children with dyslexia during a phoneme task: Before but not after treatment. Journal of Neurolinguistics, 21(4), 294-304.

Rimrodt, S. L., Clements-Stephens, A. M., Pugh, K. R., Courtney, S. M., Gaur, P., Pekar, J. J., \& Cutting, L. E. (2009). Functional MRI of Sentence Comprehension 
in Children with Dyslexia: Beyond Word Recognition. Cerebral Cortex, 19(2), 402-413.

Shastry, B. S. (2007). Developmental dyslexia: an update. Journal of Human Genetics, 52(2), 104-109.

Shaywitz, S. (2003). Overcoming Dyslexia: A New and Complete Science-Based Program for Reading Problems at Any Level. New York: Alfred A. Knopf.

Shaywitz, B. A., Shaywitz, S. E., Pugh, K. R., Mencl, W. E., Fulbright, R. K., Skudlarski, P., ... others. (2002). Disruption of posterior brain systems for reading in children with developmental dyslexia. Biological Psychiatry, 52(2), 101-110.

Shaywitz, S. E., \& Shaywitz, B. A. (2005). Dyslexia (Specific Reading Disability). Biological Psychiatry, 57(11), 1301-1309.

Shaywitz, S. E., Shaywitz, B. A., Pugh, K. R., Fulbright, R. K., Constable, R. T., Mencl, W. E., ... Gore, J. C. (1998). Functional disruption in the organization of the brain for reading in dyslexia. Proceedings of the National Academy of Sciences of the United States of America, 95(5), 2636-2641. https://doi.org/10.1073/pnas.95.5.2636.

Skottun, B. C. (2000). The magnocellular deficit theory of dyslexia: the evidence from contrast sensitivity. Vision Research, 40(1), 111-127.

Snowling, M. J. (1995). Phonological processing and developmental dyslexia. Journal of Research in Reading, 18, 132-138.

Snowling, M. J. (2000). Dyslexia. Wiley.

Stein, J. (2001). The magnocellular theory of developmental dyslexia. Dyslexia, 7(1), $12-36$.

Stein, J., \& Glickstein, M. (1992). Role of the cerebellum in visual guidance of movement. Physiological Reviews, 72(4), 967-1017.

Stein, J., Talcott, J., \& Walsh, V. (2000). Controversy about the visual magnocellular deficit in developmental dyslexics. Trends in Cognitive Sciences, 4(6), 209-210.

Tallal, P., Miller, S. L., Bedi, G., Byma, G., Wang, X., Nagarajan, S. S., Merzenich, M. M. (1996). Language Comprehension in Language-Learning Impaired Children Improved with Acoustically Modified Speech. Science, 271(5245), 81-84.

Thomson, B., Crewther, D. P., \& Crewther, S. G. (2006). Wots that werd? Pseudowords (non-words) may be a misleading measure of phonological skills in young learner readers. Dyslexia, 12(4), 289-299.

Tunmer, W. E., \& Greaney, K. (2010). Defining Dyslexia. Journal of Learning Disabilities, 43(3), 229-243.

Uodej, M. (2016). Dyslexia in First and Foreign Language Learning: A Cross-Linguistic Approach. Cambridge Scholars Publishing.

Vellutino, F. R., Fletcher, J. M., Snowling, M. J., \& Scanlon, D. M. (2004). Specific reading disability (dyslexia): what have we learned in the past four decades? Journal of Child Psychology and Psychiatry, 45(1), 2-40.

Whitebread, D. (2002). The Psychology of Teaching and Learning in the Primary School. Routledge.

Wimmer, H., Mayringer, H., \& Landerl, K. (2000). The double-deficit hypothesis and difficulties in learning to read a regular orthography. Journal of Educational Psychology, 92(4), 668.

Wolf, M., \& Bowers, P. G. (2000). Naming-Speed Processes and Developmental Reading Disabilities: An Introduction to the Special Issue on the Double-Deficit Hypothesis. Journal of Learning Disabilities, 33(4), 322-324. 
Wolf, M., Bowers, P. G., \& Biddle, K. (2000). Naming-Speed Processes, Timing, and Reading: A Conceptual Review. Journal of Learning Disabilities, 33(4), 387-407.

World Helth Organization. (1993).ICD Classification of Mental and Behavioral Disorders: Diagnostic Criteria for Research. Geneva, Switzerland.

Recebido em: 10/03/2019 Aceito em: 06/07/2019 